\title{
Putative Stem Cells in Human Dental Pulp with Irreversible Pulpitis-An Exploratory Study
}

\author{
Z. Wang ${ }^{1,2,6, \S,}{ }^{*}$, J. Pan ${ }^{1,5, \S}$, JT Wright ${ }^{1,2}$, S. Bencharit ${ }^{1}$, S. Zhang ${ }^{1}$, ET Everett ${ }^{1,2}$, FB \\ Teixeira $^{4,7}$, and JS Preisser ${ }^{3}$ \\ ${ }^{1}$ Dental Research Center, The University of North Carolina at Chapel Hill, Chapel Hill, NC 27599 \\ ${ }^{2}$ Department of Pediatric Dentistry, The University of North Carolina at Chapel Hill, Chapel Hill, \\ NC 27599 \\ ${ }^{3}$ Department of Biostatistics, The University of North Carolina at Chapel Hill, Chapel Hill, NC \\ 27599 \\ ${ }^{4}$ Department of Endodontics, The University of North Carolina at Chapel Hill, Chapel Hill, NC \\ 27599 \\ ${ }^{5}$ Department of Oral and Maxillofacial Surgery, West China Hospital of Stomatology, Sichuan \\ University, Chengdu, 610041, China \\ ${ }^{6}$ Department of Orthodontics and Pediatric Dentistry, University of Michigan, 48109
}

\section{Abstract}

\begin{abstract}
Introduction-Although human dental pulp stem cells isolated from healthy teeth have been extensively characterized, it is unknown whether stem cells also exist in clinically compromised teeth with irreversible pulpitis. Here we explored whether cells retrieved from clinically compromised dental pulp have stem cell-like properties.
\end{abstract}

\begin{abstract}
Methods-Pulp cells were isolated from healthy teeth (control group) and from teeth with clinically diagnosed irreversible pulpitis (diseased group). Cell proliferation, stem cell marker STRO-1 expression and cell odonto-osteo-genic differentiation competence were compared.

Results-Cells from the diseased group demonstrated decreased colony formation capacity and a slightly decreased cell proliferation rate but had similar STRO-1 expression, and exhibited a similar percentage of positive ex vivo osteogenic induction and dentin sialophosphoprotein expression from STRO-1-enriched pulp cells.
\end{abstract}

Conclusion-Our study provides preliminary evidence that clinically compromised dental pulp may contain putative cells with certain stem cell properties. Further characterization of these cells will provide insight regarding whether they could serve as a source of endogenous multipotent cells in tissue regeneration based dental pulp therapy.

\footnotetext{
(C) 2010 American Association of Endodontics. Published by Elsevier Inc. All rights reserved.

*corresponding author, zhengyan@umich.edu, Zhengyan Wang DDS, MS, PhD, Department of Orthodontics and Pediatric Dentistry, School of Dentistry, University of Michigan, 1011 North University, Ann Arbor, MI 48109-1078, Phone: 734-764-8451, Fax: 734-763-8100.

7 current address: Department of Endodontics, University of Texas Health Science Center at San Antonio, San Antonio, TX

$\S_{\text {these authors contributed equally to this work }}$

Publisher's Disclaimer: This is a PDF file of an unedited manuscript that has been accepted for publication. As a service to our customers we are providing this early version of the manuscript. The manuscript will undergo copyediting, typesetting, and review of the resulting proof before it is published in its final citable form. Please note that during the production process errors may be discovered which could affect the content, and all legal disclaimers that apply to the journal pertain.
} 


\section{Keywords}

irreversible pulpitis; dental pulp; stem cell

\section{INTRODUCTION}

Pulpitis-associated pain contributes to a substantial financial and societal burden and affects quality of life. In addition to pain and suffering, pulp infection can also cause severe, and at times, even fatal systemic infection (1). Appropriate management of dental pulp infection and inflammation has tremendous significance in maintaining general health. Although immediate treatment is indispensable for a better prognosis, current endodontic therapies typically lead to destroying or compromising pulp vitality. In adult teeth, even when the lesion affects only part of the pulp, the entire pulp tissue is often removed (root canal therapy). The resulting non-vital teeth often require extensive restorations, which in turn increases the cost and the risk of complications. In primary teeth, pulpotomy treatment involves application of formaldehyde, a toxic, mutagenic chemical that can be absorbed into the body $(2,3)$. Therefore, it is important to develop biocompatible treatments directed at maintaining pulp vitality and increasing tooth longevity.

The discovery of dental pulp stem cells has important implications in both medical and dental fields. Postnatal dental pulp stem cells (DPSCs) $(4,5)$, stem cells from exfoliated deciduous teeth (SHED) (6), and stem cells from the apical papilla (SCAP) $(7,8)$, have stem cell properties including multipotent and self-renewal capacities. They are able to differentiate into a variety of cell types including odontoblasts in vitro $(4,9)$ and form dentin/ pulp-like complexes in vivo $(5,10)$. DPSCs and SCAP also have self-renewal capacity evidenced by animal studies with human cell transplants $(9,11)$, particularly, human SCAP and DPSCs can regenerate a pulp-like structure de novo with established vascularity and dentin formation when transplanted in a tooth fragment carrier (11). The discovery of DPSCs and SCAP makes it possible to develop a biocompatible treatment based on endogenous pulp repair or regeneration.

However, when a dental pulp is diagnosed with "irreversible pulpitis", the available pulp tissue is believed to be inflamed or infected. In this regard, it is unknown whether these damaged dental pulps still contain stem cells with competent proliferation and differentiation capacities. Answering these questions is critical for the development of autologous stem cell based pulp therapy strategies to achieve in situ regeneration with optimal growth factors and matrix. In this exploratory study, we hypothesized that the pulp cells residing in pulp clinically diagnosed with "irreversible pulpitis" may still have stem cell potential similar to healthy pulp cells and therefore might be a resource for autologous pulp regeneration.

\section{MATERIALS AND METHODS}

\section{Subjects}

Pulp tissues were obtained from permanent teeth of patients (6-40 years of age) recruited from outpatient clinics of the University of North Carolina at Chapel Hill (UNC-CH) School of Dentistry under a protocol approved through the Institutional Research Board committee of UNC-CH following consent. Healthy pulp tissues were collected from $\mathrm{n}=8$ patients undergoing orthodontic molar extraction (control group). All teeth were free of carious lesion. Compromised dental pulps were obtained from $n=8$ patients with irreversible pulpitis (diseased group) that required treatment procedures to remove pulp tissue from involved teeth. The diagnosis of irreversible pulpitis was determined by endodontic specialists based 
on clinical assessment, including history of spontaneous pain and intense, lingering pain to cold stimulus. The vitality of the pulp was confirmed upon access. Teeth with completely necrotized pulp tissue were excluded.

\section{Cell Culture}

Healthy dental pulp tissue was harvested as previously described $(5,12)$. Extracted healthy teeth were sterilized with iodine and scaled thoroughly to remove all periodontal and periapical tissue before drilled and sectioned in half to obtain pulp tissue. Diseased pulp tissues were collected from pulp chambers with a sterile broach after complete exposure of pulp chamber and transferred into sterile $\alpha$-Minimum Essential Medium with $2 \mathrm{mM} \mathrm{L-}$ glutamine ( $\alpha$-MEM, Gibco) penicillin and streptomycin. All pulp tissues were washed with $\alpha$-MEM with $10 \%$ fetal bovine serum (FBS, Gibco), digested and cultured as described $(5,12)$. Antibiotics (penicillin and streptomycin) were used in all washing, digesting buffer and culture media to minimize bacteria contamination. Primary cells were passed to second passage (named passage 1, P1), a portion of which was cryopreserved for later expansion. P2-P5 cells were used in most in vitro assays. Each control and diseased pulp tissue was processed, cultured and evaluated separately in all experiments.

\section{Single Cell Derived Colony Formation Assay}

To assess single cell derived colony formation efficiency, primary cells were seeded into 6 well plates at a live cell concentration of $0.5 \times 10^{5} / \mathrm{ml}$ as described above. Single cell derived colonies were defined as those units with more than 50 cells. The number of colonies was counted on the day before colonies would merge together, usually between days 13-16. For those samples with limited colonies, the number was counted as late as 21 days of culture.

\section{BrdU Cell Proliferation Rate Assay}

Cells from each sample were seeded onto three coverslips in 6 well plates and cultured till fully attached. Then the cells were starved in serum free medium for $24 \mathrm{hr}$ before adding back normal medium with Bromodeoxyuridine (BrdU, Roche). Proliferation was evaluated after $24 \mathrm{hr}$ according to the Zymed BrdU attaining kit instruction (Invitrogen, CA). Briefly, BrdU incorporation was detected by a biotinylated monoclonal anti-BrdU antibody. Staining was visualized after adding streptavidinperoxidase and diaminobenzidine (DAB). Positive cell percentage in each coverslip was recorded by counting cells in 5 randomly selected fields under a light microscope (Nikon ECLIPS TS100, Japan). The average BrdU positive cells percentage of each sample was calculated and mean value from each group were compared.

\section{STRO-1 Expression Evaluation and STRO-1 Positive cell Purification}

STRO-1 has been used as a stromal stem cell surface marker in characterizing stem cell composition in mesenchymal stem cells (13). To investigate whether diseased dental pulp still contains presumptive progenitor cells, we evaluated STRO-1 expression on expanded cells by flow cytometry. Cells from each patient sample were harvested at $70 \%$ confluence, washed, blocked in $10 \%$ FBS on ice for $1 \mathrm{hr}$ at $5 \times 10^{6} / \mathrm{ml}$, then incubated with anti-human STRO-1 mouse monoclonal antibody (Chemicon) or control IgM for $1 \mathrm{hr}$ on ice. After washes with PBS, cells were incubated with Alex-488 conjugated goat anti-mouse IgG (Invitrogen) for $30 \mathrm{~min}$ on ice. Cells were washed and resuspended in PBS before analysis by a FACStar Plus flow cytometer (Becton Dickinson). The percentage of cells positive for STRO-1 from each sample was recorded.

To obtain enriched STRO-1 positive cells, Dynabead positive isolation method was used as previously described to obtain an enriched STRO-1-positive cell population $(10,14)$. Briefly, 
cells were blocked with $10 \%$ FBS-PBS at $1 \times 10^{7} / \mathrm{ml}$ for $30 \mathrm{~min}$ on ice and incubated with mouse anti-human STRO-1 antibody for $20 \mathrm{~min}$ at $4^{\circ} \mathrm{C}$ with rocking, then washed and resuspended at $1 \times 10^{7}$ cells $/ \mathrm{ml}$ in $10 \%$ FBS-PBS with $2 \mathrm{mM}$ EDTA before adding antimouse IgM Dynabeads (Invitrogen) with 1:4 target cell/Dynabead ratio. STRO-1 enriched cell pellets were obtained by magnetic pull down after 20 min incubation and subsequent washing and culture in regular medium.

\section{Odonto-osteo-genic Differentiation}

STRO-1 purified cells were seeded on 24-well plates and cultured until confluence was achieved prior to incubation in osteogenic/odontogenic induction medium, which contains $10 \mathrm{mM} \beta$-glycerophosphate, $10 \mathrm{nM}$ dexamethasone and $50 \mu \mathrm{g} / \mathrm{ml} \mathrm{L}$-ascorbic 2 - phosphate in $\alpha$-MEM with $10 \%$ FBS $(5,15-17)$. Cells cultured in regular medium were used as control. After induction for 3-4 weeks, cell cultures were fixed and assayed for mineral deposition by Alizarin Red staining (Ricca Chemical Company, TX) $(18,19)$. Samples with positive mineral nodules were recorded as odonto-osteo-genic positive. Odontogenic differentiation was also analyzed by real time quantitative reverse transcript PCR (RT-PCR) for the expression of dentin sialophosphoprotein (DSPP) and dental matrix protein 1 (DMP1) $(20,21)$. Total RNA was isolated and cDNA was synthesized from lug of isolated RNA using with the Omniscript RT kit (Qiagen) by random decamer primers (Applied Biosystems/Ambion). Real time quantitative RT-PCR was performed with $1 \mu \mathrm{L}$ synthesized cDNA, TagMan Universal PCR Mix, and 20X on-demand primers specific for DSPP and DMP1 genes in triplicates with ABI PRISM 7000 Detection System apparatus (Applied Biosystem). Amplification of glyceraldehydes-3-phosphate dehydrogenase (GAPDH) from each sample was included as internal control. The relative quantity of DSPP and DMP1 mRNA expression upon osteo-odonto-induction were calculated against GAPDH RNA value (22).

\section{Statistical Analysis}

Wilcoxon Rank Sum test, two sample Student t-test and Fisher's exact test were used in statistical analysis and p-value less than 0.05 was considered significant.

\section{RESULTS}

Eight subjects were recruited in each of the control and diseased groups. There was no significant difference in the average age between two groups. All teeth in the diseased group had post-caries irreversible pulpitis confirmed by positive cold tests and bleeding during debridement, with history of spontaneous pain that ranged from 1 day to two months (average duration of 25 days).

\section{Cells from Pulp with Irreversible Pulpitis (Diseased Group) Formed Single Cell Derived Colonies In Vitro, with Lower Frequencies Than Healthy Controls}

Almost all single cell-derived colonies emerged at day 5 to 6 in the control group and at day 7 to 8 in the diseased group. One sample in the diseased group did not have any cell growth and another sample did not form colonies despite having fibroblast-like cell growth. Cells within each colony showed typical fibroblast-like morphology, with colony or cell morphology being similar between the control and diseased groups (Fig. 1A). However, the frequency of single cell derived colony formation in diseased group ( $4.7 \pm 5.9$ per plate) was significantly lower than that of control group $(36.0 \pm 26.1, \mathrm{p}<0.05)$ (Figure 1B). This indicates that stem cells containing proliferative capacity still exist in compromised pulp tissue; however, the number of those cells is significantly decreased. 


\section{Cells from Diseased Group Exhibited Slightly Lower Cell Proliferation Rate Than Control Group}

The average percentage of BrdU positive cells in the control group $(84 \pm 9 \%, \mathrm{n}=7)$ was significantly higher than that of the diseased group $(58 \pm 25 \%, n=6, p<0.05)$ (Figure $1 C)$. Direct cell counting (data not shown) also demonstrated that diseased pulp cells exhibit a lower proliferation potential than healthy pulp cells in expanded passages.

\section{Cells from Diseased Group Exhibits Comparable STRO-1 Expression as That From Control Group}

Expanded cells from the diseased group had a similar percentage of STRO-1 positive population $(13.9 \pm 6.2 \%)$ compared to the control group (11.1 \pm 5.7$)$ (Figure 2). This suggests that comparable percentage of presumptive progenitor cells still exist even when the dental pulp tissue is extremely compromised.

\section{Differentiation Competence of Ex Vivo Expanded DPSCs In Vitro}

To investigate whether those STRO-1 positive cells from the diseased group still have the ability to differentiate into dentin-forming cells, we evaluated their in vitro odontogenic differentiation potential. Most samples of both groups (5 out of 7 samples in the control group and 5 out of 6 samples in the diseased group) had positive mineralization staining, indicating competent odonto-osteo-genic differentiation of STRO-1 positive cell population in both groups (Figure 3A). There was no significant difference in the percentage of samples exhibiting mineral deposition between control and diseased group. However, variations in the quantity of mineralization were noted, especially in the diseased group (data not shown). qRT-PCR showed no statistically significant difference in DSPP gene expression (Figure 3B). DMP1 gene expression was not detected in either group.

\section{DISCUSSION}

DPSCs are able to form dentin and a pulp-like complex, making them multipotent, and an excellent source for dental pulp tissue regeneration. However, when patients have a toothache with irreversible pulpitis, the available pulp is usually in an inflamed condition. This clinically compromised dental pulp was long believed to have no value and was therefore discarded during treatment. Our study shows that diseased pulp contains viable cells with the potential for ex vivo expansion and proliferation, with a similar percentage of STRO-1 positive cells and ex vivo odonto-osteo-genic differentiation capacity, suggesting that even clinically compromised dental pulp tissues may have putative stem cells that could be used in endogenous pulp regeneration. In addition, our results also indicate that the usually discarded pulp tissue during endodontic therapy may be used in research on stem cell therapy for other diseases.

We observed low frequency of single cell derived colony formation in primary culture in the diseased group. This is likely due to the decreased cell proliferation rate and stem cell number. In addition, cell component may change during inflammation due to increased vascular permeability. There is increased inflammatory and blood cell infiltration in the pulp tissue which can lead to alteration of stem cell ratio in the primary cell culture. It is not clear why cells from two diseased samples did not form colony in primary culture given the fact that patients' ages and clinical presentations were similar to other samples in the diseased group. Although statistically significant, proliferation rate of diseased pulp cells was just slightly lower than the control in expanded passages, indicating that proliferation potential is slightly compromised, but still robust. Interleukin-1 beta, an inflammatory mediator, has inhibitory effects on pulpal fibroblastic proliferation through the induction of prostaglandin E2 synthesis (23). Therefore, inflammatory mediators present in the diseased pulp may play 
an important role in altering the proliferation and colony formation rate in the stem cells. STRO-1 expression levels in our study are comparable to similar study (6). Interestingly, diseased pulp exhibited a slightly higher STRO-1 expression although it is not statistically significant.

The discrepancy between low colony formation frequencies, slightly compromised proliferation potential and similar STRO-1 expression in diseased cells indicating that inflammation might affect stem cell proliferation and/or recruitment. Inflammation derived stromal cell-derived factor 1 alpha (SDF-1 $\alpha$ ) and its receptor CXC chemokine receptor 4 (CXCR4) are known that can direct migration of stem cells to injury site in central nervous system (24) or myocardium (25). Inflamed pulp expresses high level of SDF-1/CXCR4 $(26,27)$, indicating that inflammation may also play a role in stem cell recruitment in dental pulp. This needs further detailed basic cell biology research to confirm.

Upon examining STRO-1 purified pulp cells, we found no difference in odontodifferentiation between the control and diseased groups via a qualitative test evaluating positive rate in each group. Due to a limited sample size and variation in the extent of pulpal inflammation in the diseased group, it was difficult to compare mineralization activities quantitatively. However, we did observe that the diseased group had a higher variability in the degree of mineralization. These variations may result from various degrees of inflammation, patient age and tooth developmental stage, etc. within the diseased group. How inflammation affects progenitor cell differentiation capacity is not clearly understood; however, mild inflammation was believed to enhance odontoblastic and osteoblastic differentiation and matrix formation, while severe inflammation was believed to induce apoptosis of these stem cells (28). With information gained from current study, future study using established cell culture and well-controlled inflammation intervention (like LPS, TNFalpha, etc) should be done to evaluate how inflammation affects stem cell osteo-genic differentiation potential qauntatively.

We could not detect DMP1 gene expression while DSPP expression is robust. We believe this is probably due to the timing that we evaluate gene expression after osteoinduction for 3-4 weeks when mineral nodules were formed. DMP1 expression seems to be more temporal sensitive $(29,30)$. DMP1 and DSPP both are expressed in young odontoblasts, but at later stage after appearance of mineral, DMP1 expression is greatly decreased while DSPP continue to have high-level expression (30). Therefore, it is very likely DMP1 expression was greatly decreased at our evaluation point.

This study is an exploratory study aiming to determine if cells from diseased dental pulp have stem cell-like properties and the potential to differentiate into dentin-forming functional pulp cells. There is limited information regarding whether clinically compromised teeth contain functional DPSCs. Our findings are consistent with a recent study showing that teeth with complicated crown fracture also have functional DPSCs (31). Future studies incorporating in vitro and in vivo multilineage differentiation assays including odontogensis and angiogenesis are indicated to fully characterize these cells. Studies with larger sample size are necessary to correlate the degree of inflammation and clinical presentation with cell proliferation and/or differentiation competence. This will help set clinical guidelines to predict whether a given diseased pulp has stem cells that retain the potential to proliferate and differentiate. Additionally, determination of appropriate growth factors and matrix to facilitate regeneration is required to achieve in situ endogenous stem cell based regeneration.

In conclusion, our exploratory study suggests the existence of functional putative stem cells in clinically compromised dental pulp with irreversible pulpitis. Further characterization of 
these cells will provide insight regarding whether they could serve as a source of endogenous multipotent cells in tissue regeneration based dental pulp therapy.

\section{Acknowledgments}

The authors deny any financial affiliations related to this study or its sponsors. This worked was supported by NIH 1T32DE017245 (ZW), Dean's fund and Faculty Creativity Fund from School of Dentistry at UNC-CH (ZW)

\section{References}

1. Otto M. A Boy's Death-How could a toothache have such a tragic outcome? The Washington Post. 2007 Sect. B01.

2. Myers DR, Shoaf HK, Dirksen TR, Pashley DH, Whitford GM, Reynolds KE. Distribution of 14Cformaldehyde after pulpotomy with formocresol. J Am Dent Assoc 1978;96(5):805-813. [PubMed: 418090]

3. Pashley EL, Myers DR, Pashley DH, Whitford GM. Systemic distribution of 14C-formaldehyde from formocresol-treated pulpotomy sites. J Dent Res 1980;59(3):602-608. [PubMed: 6937493]

4. Gronthos S, Brahim J, Li W, Fisher LW, Cherman N, Boyde A, et al. Stem cell properties of human dental pulp stem cells. J Dent Res 2002;81(8):531-535. [PubMed: 12147742]

5. Gronthos S, Mankani M, Brahim J, Robey PG, Shi S. Postnatal human dental pulp stem cells (DPSCs) in vitro and in vivo. Proc Natl Acad Sci U.S.A 2000;97(25):13625-13630. [PubMed: 11087820]

6. Miura M, Gronthos S, Zhao M, Lu B, Fisher LW, Robey PG, et al. SHED: stem cells from human exfoliated deciduous teeth. Proc Natl Acad Sci U.S.A 2003;100(10):5807-5812. [PubMed: 12716973]

7. Sonoyama W, Liu Y, Yamaza T, Tuan RS, Wang S, Shi S, et al. Characterization of the apical papilla and its residing stem cells from human immature permanent teeth: a pilot study. J Endod 2008;34(2):166-171. [PubMed: 18215674]

8. Huang GT, Sonoyama W, Liu Y, Liu H, Wang S, Shi S. The hidden treasure in apical papilla: the potential role in pulp/dentin regeneration and bioroot engineering. J Endod 2008;34(6):645-651. [PubMed: 18498881]

9. Batouli S, Miura M, Brahim J, Tsutsui TW, Fisher LW, Gronthos S, et al. Comparison of stem-cellmediated osteogenesis and dentinogenesis. J Dent Res 2003;82(12):976-981. [PubMed: 14630898]

10. Shi S, Gronthos S. Perivascular niche of postnatal mesenchymal stem cells in human bone marrow and dental pulp. J Bone Miner Res 2003;18(4):696-704. [PubMed: 12674330]

11. Huang G, Yamaza T, Shea LD, Djouad F, Kuhn NZ, Tuan R, et al. Stem/progenitor Cell-Mediated De Novo Regeneration of Dental Pulp with Newly Deposited Continuous Layer of Dentin in an In Vivo Model. Tissue Eng Part A. 2009

12. Liu H, Gronthos S, Shi S. Dental pulp stem cells. Methods Enzymol 2006;419:99-113. [PubMed: 17141053]

13. Gronthos S, Zannettino AC. A method to isolate and purify human bone marrow stromal stem cells. Methods Mol Biol 2008;449:45-57. [PubMed: 18370082]

14. Bensidhoum M, Chapel A, Francois S, Demarquay C, Mazurier C, Fouillard L, et al. Homing of in vitro expanded Stro-1- or Stro-1+ human mesenchymal stem cells into the NOD/SCID mouse and their role in supporting human CD34 cell engraftment. Blood 2004;103(9):3313-3319. [PubMed: 14715641]

15. Zhang W, Walboomers XF, Shi S, Fan M, Jansen JA. Multilineage Differentiation Potential of Stem Cells Derived from Human Dental Pulp after Cryopreservation. Tissue Eng. 2006

16. Zhang W, Walboomers XF, Shi S, Fan M, Jansen JA. Multilineage differentiation potential of stem cells derived from human dental pulp after cryopreservation. Tissue Eng 2006;12(10):2813-2823. [PubMed: 17518650]

17. Zhang W, Walboomers XF, van Kuppevelt TH, Daamen WF, Bian Z, Jansen JA. The performance of human dental pulp stem cells on different three-dimensional scaffold materials. Biomaterials 2006;27(33):5658-5668. [PubMed: 16916542] 
18. Tsukamoto Y, Fukutani S, Shin-Ike T, Kubota T, Sato S, Suzuki Y, et al. Mineralized nodule formation by cultures of human dental pulp-derived fibroblasts. Arch Oral Biol 1992;37(12):10451055. [PubMed: 1335227]

19. Gregory CA, Gunn WG, Peister A, Prockop DJ. An Alizarin red-based assay of mineralization by adherent cells in culture: comparison with cetylpyridinium chloride extraction. Anal Biochem 2004;329(1):77-84. [PubMed: 15136169]

20. Iejima D, Sumita Y, Kagami H, Ando Y, Ueda M. Odontoblast marker gene expression is enhanced by a CC-chemokine family protein MIP-3alpha in human mesenchymal stem cells. Arch Oral Biol 2007;52(10):924-931. [PubMed: 17532291]

21. Otaki S, Ueshima S, Shiraishi K, Sugiyama K, Hamada S, Yorimoto M, et al. Mesenchymal progenitor cells in adult human dental pulp and their ability to form bone when transplanted into immunocompromised mice. Cell Biol Int 2007;31(10):1191-1197. [PubMed: 17524678]

22. Livak KJ, Schmittgen TD. Analysis of relative gene expression data using real-time quantitative PCR and the 2(-Delta Delta C(T)) Method. Methods 2001;25(4):402-408. [PubMed: 11846609]

23. Lertchirakarn V, Birner R, Messer HH. Effects of interleukin-1 beta on human pulpal fibroblast proliferation and collagen synthesis. J Endod 1998;24(6):409-413. [PubMed: 9693584]

24. Imitola J, Raddassi K, Park KI, Mueller FJ, Nieto M, Teng YD, et al. Directed migration of neural stem cells to sites of CNS injury by the stromal cell-derived factor 1alpha/CXC chemokine receptor 4 pathway. Proc Natl Acad Sci U S A 2004;101(52):18117-18122. [PubMed: 15608062]

25. Abbott JD, Huang Y, Liu D, Hickey R, Krause DS, Giordano FJ. Stromal cell-derived factor-1alpha plays a critical role in stem cell recruitment to the heart after myocardial infarction but is not sufficient to induce homing in the absence of injury. Circulation 2004;110(21):33003305. [PubMed: 15533866]

26. Jiang HW, Ling JQ, Gong QM. The expression of stromal cell-derived factor 1 (SDF-1) in inflamed human dental pulp. J Endod 2008;34(11):1351-1354. [PubMed: 18928845]

27. Jiang L, Zhu YQ, Du R, Gu YX, Xia L, Qin F, et al. The expression and role of stromal cellderived factor-1alpha-CXCR4 axis in human dental pulp. J Endod 2008;34(8):939-944. [PubMed: 18634924]

28. Goldberg M, Farges JC, Lacerda-Pinheiro S, Six N, Jegat N, Decup F, et al. Inflammatory and immunological aspects of dental pulp repair. Pharmacol Res 2008;58(2):137-147. [PubMed: 18602009]

29. Yasuhara R, Suzawa T, Miyamoto Y, Wang X, Takami M, Yamada A, et al. Nitric oxide in pulp cell growth, differentiation, and mineralization. J Dent Res 2007;86(2):163-168. [PubMed: 17251517]

30. D'Souza RN, Cavender A, Sunavala G, Alvarez J, Ohshima T, Kulkarni AB, et al. Gene expression patterns of murine dentin matrix protein 1 (Dmp1) and dentin sialophosphoprotein (DSPP) suggest distinct developmental functions in vivo. J Bone Miner Res 1997;1(12):2040-2049. [PubMed: 9421236]

31. Huang AH, Chen YK, Chan AW, Shieh TY, Lin LM. Isolation and characterization of human dental pulp stem/stromal cells from nonextracted crown-fractured teeth requiring root canal therapy. J Endod 2009;35(5):673-681. [PubMed: 19410081]

32. Kenward MG, Roger JH. Small sample inference for fixed effects from restricted maximum likelihood. Biometrics 1997;53(3):983-997. [PubMed: 9333350] 
Control Group
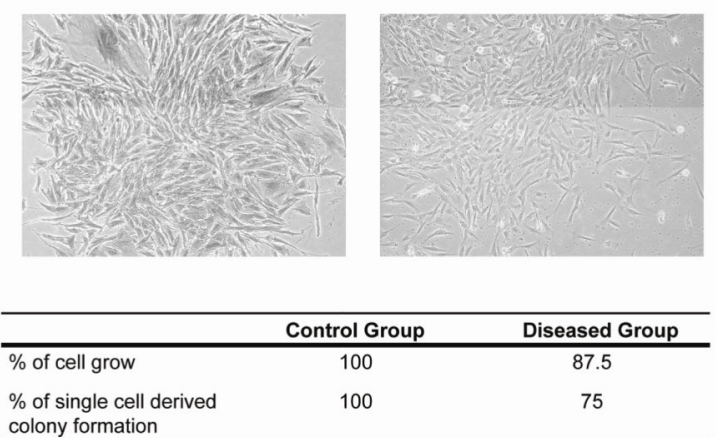
colony formation

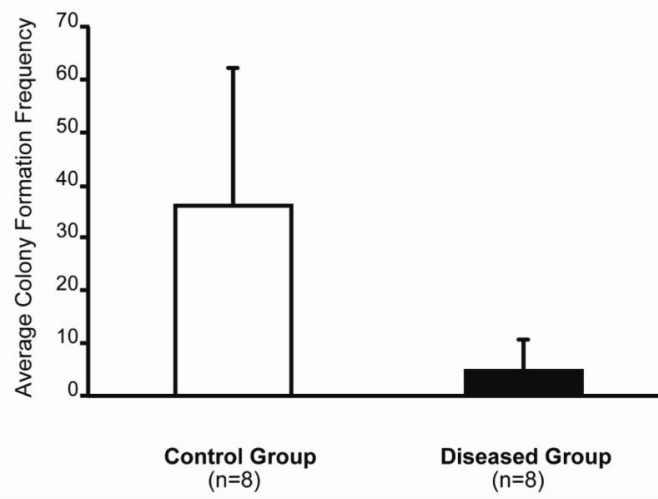

C

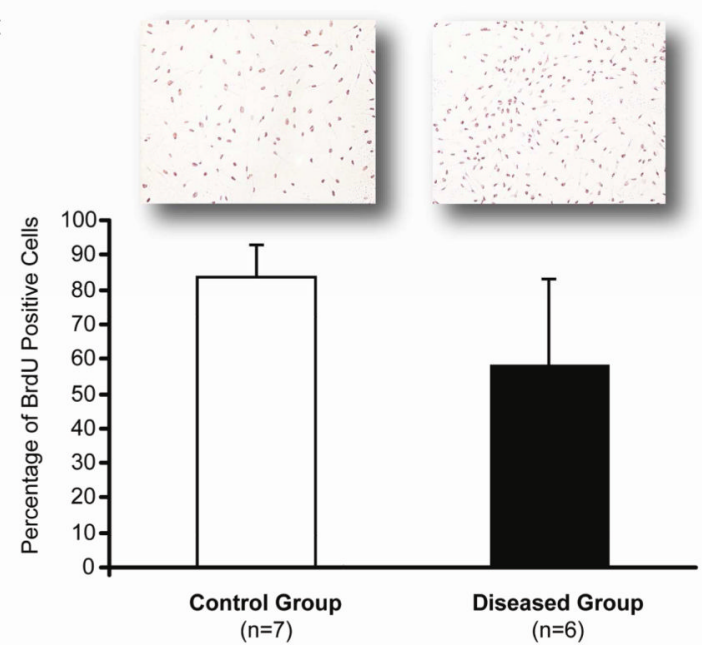

Figure 1. Single cell derived colony formation in primary culture and cell proliferation in expanded cultures from both control and diseased groups

A: Colony morphology is similar in control and diseased groups. Pictures show part of a colony, taken between days 10-14 (objective 10×). B. Colony formation frequency was defined as the number of units with more than 50 cells. Cultures were fixed with $10 \%$ buffered formalin phosphate between days 10 to 21 and then stained with $0.1 \%$ crystal violet. Each experiment was performed in triplicates. Wilcoxon Rank Sum test, $\mathrm{p}=0.021$; ratio of means (i.e., fold change) $90 \%$ CI $(3.1,18.8)$. C. The average percentage of BrdU positive cells in each group was calculated. BrdU was incorporated into proliferating cells and then detected by a monoclonal anti-BrdU. The percentage of positive cells of each 
sample was recorded by counting 5 randomized fields (objective $10 \times$ or $20 \times$ ) and the mean percentage of positive cells was compared. Pictures are representative examples from each group taken at 10x. Error bars represent standard deviation. Wilcoxon Rank Sum test, $\mathrm{p}=0.036$; fold change $90 \% \mathrm{CI}(1.04,2.01)$. 

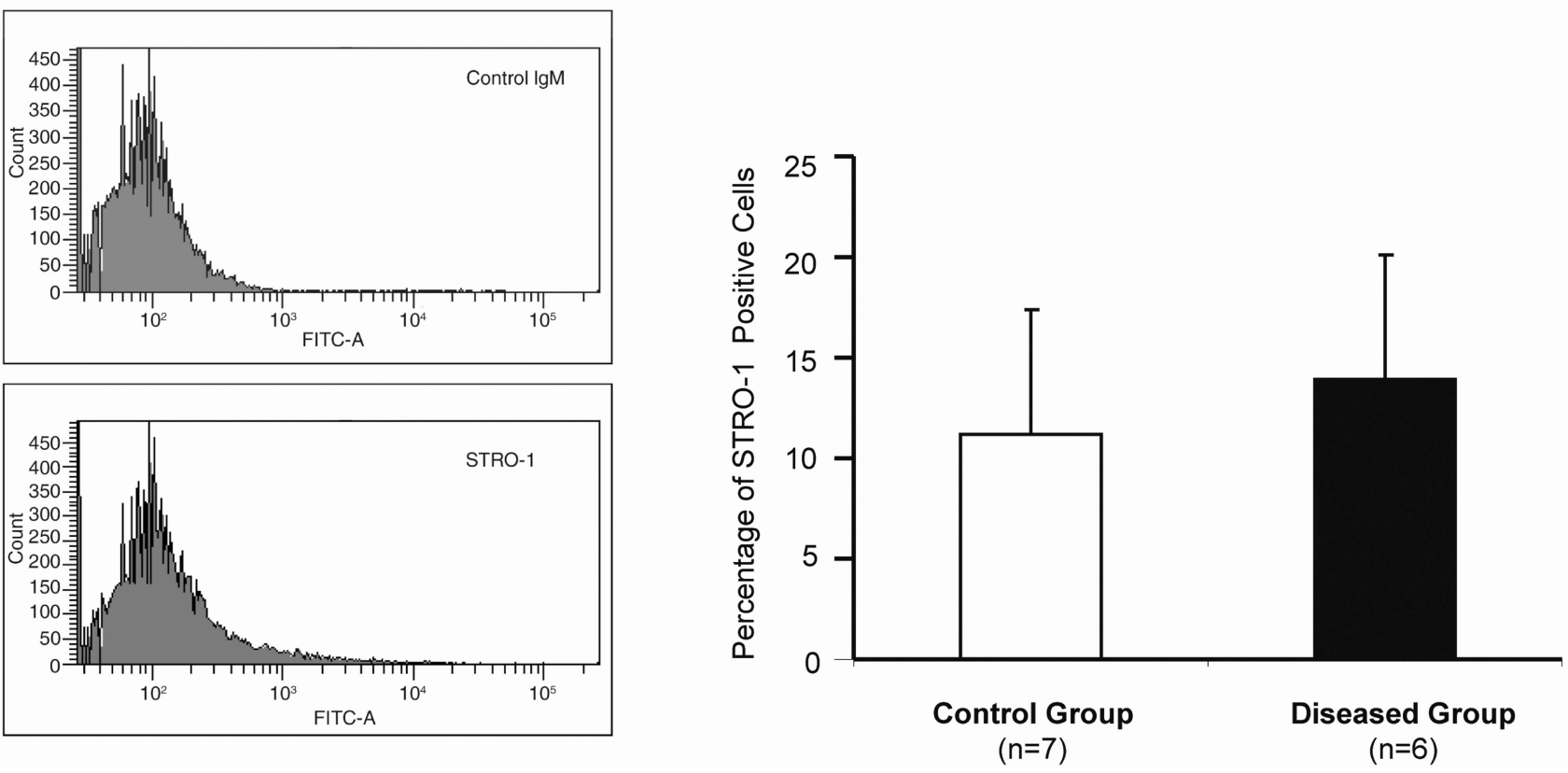

Figure 2. Diseased pulp cells exhibit similar STRO-1 expression to that of control cells Cell suspension from expanded culture was collected and pre-incubated with mouse antihuman STRO-1 monoclonal antibody followed by incubation with Alexa-488-labelled goat anti-mouse IgG, and then evaluated by flow cytometery. A. Histogram of a sample from diseased group at FL-1 channel for Alexa-488 fluorescence intensity. B. Percentages of STRO-1 positive cells were documented in each sample with the negative control set at $5 \%$ and mean value from each group was calculated. Error bars represent standard deviation. Wilcoxon Rank Sum test, $\mathrm{p}=0.387,90 \%$ CI $(0.51,1.26)$. 
A

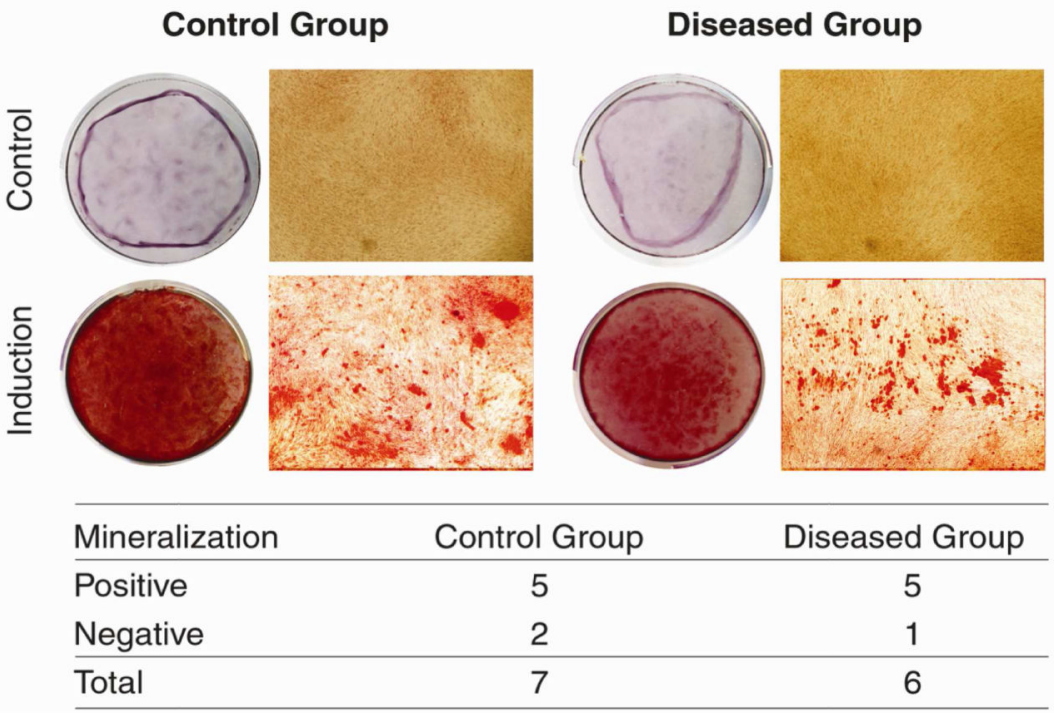

B

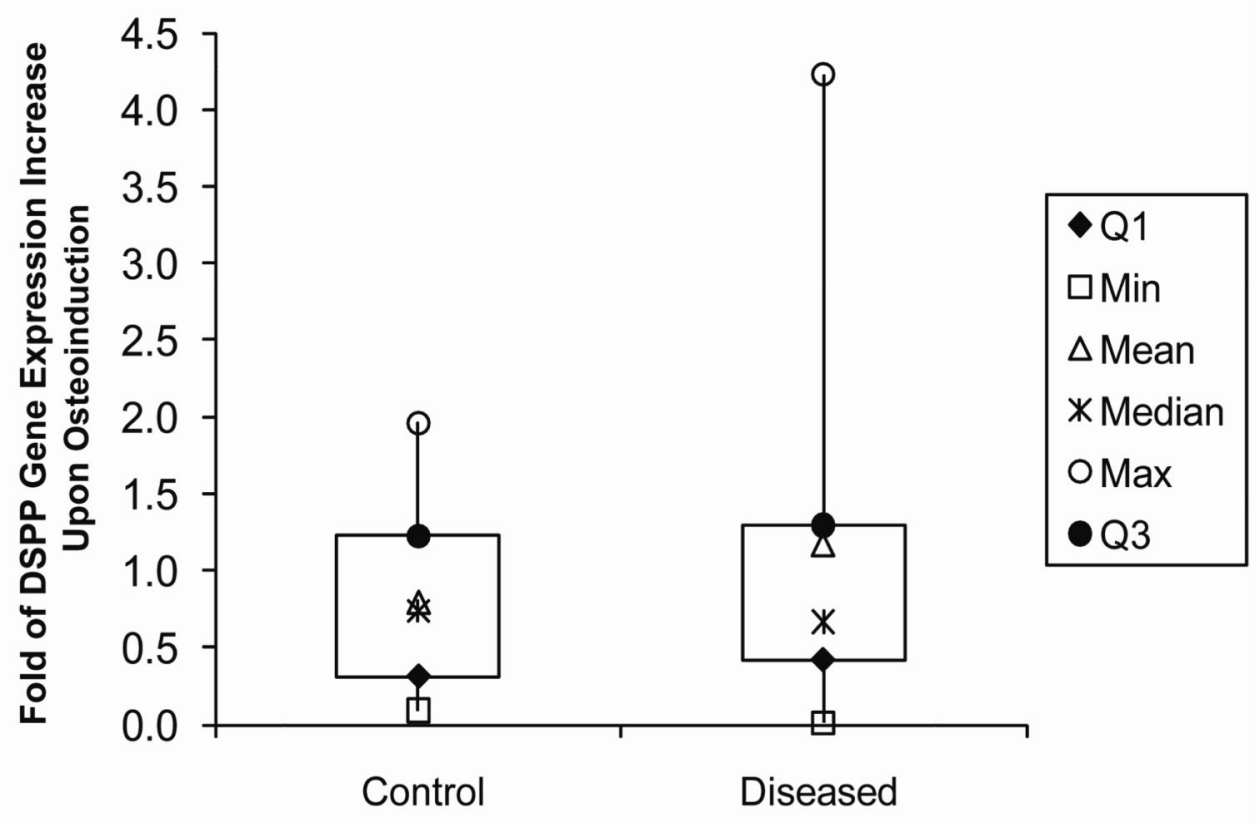

Figure 3. Osteogenic differentiation potential of STRO-1 positive pulp cells from control and diseased pulp tissue

A. Representative examples of most positive alizarin red-S stained culture 21 days after ostegenic induction in each group, and qualitative description of osteo-odonto-genic differentiation activity. Fisher's exact test, $\mathrm{p}=1.00$. B. Real time PCR analysis of DSPP gene expression, maker for odontoblast differentiation, compared to expression of GAPDH indicated as box plots (Q1-the first quartile, Q3-the third quartile, Min-minimum level, Maxmaximum level). Adjusted $t$-test based upon Kenward-Roger degrees of freedom correction (32) within a linear mixed models framework to account for multiple batches per subject and 
repeat experiments within batch (or same mRNA sample); total of 35 replicates comparing five control versus four diseased subjects, $\mathrm{p}=0.500$. 